\title{
Production and characterization of silver powder created using high-pressure water atomization
}

\author{
Takashi OGIHARA $\dagger$, Toshihiko KUBO, Shigehiro ARITA, Nobuyoshi AOYAGI, \\ Ryosuke UEYAMA, Masahiro HARADA and Akio HARADA \\ Daiken Chemical Sales \& Mfg Co., Ltd, 1-3-3 Technoport, Mikuni-cho, Sakai, Fukui 913-0038, Japan
}

\begin{abstract}
Silver powders are important for the production of silicon solar cells and low-temperature co-fired ceramics. In this study, a silver powder was produced at a rate of $2 \mathrm{~kg} / \mathrm{min}$ through water atomization with a water pressure of $80 \mathrm{MPa}$ and water flow rate of $220 \mathrm{~L} / \mathrm{min}$. Scanning electron microscopy analysis showed that the silver particles produced were aggregated and had various types of morphologies such as spherical, elliptical, and irregular. The volume average particle size and its standard deviation were 8 and $4.1 \mu \mathrm{m}$, respectively. Powder X-ray diffraction revealed that the as-prepared silver powder had a single phase with high crystallinity. The oxygen content in the silver powder measured by electron probe micro analysis was $50 \mathrm{ppm}$. The silver powder was classified to the size of $\leq 2.5 \mu \mathrm{m}$, and the shrinkage of the silver paste was $25.5 \%$ at $900^{\circ} \mathrm{C}$, comparable to that of the powder obtained by chemical reduction. Electrical measurements revealed that the specific resistivity of the silver paste sintered at $900^{\circ} \mathrm{C}$ for $60 \mathrm{~min}$ was $2.11 \times 10^{-8} \Omega \mathrm{m}$. The silver paste exhibited lower specific resistivity when the sintering temperature was high and sintering time was long.
\end{abstract}

(C2017 The Ceramic Society of Japan. All rights reserved.

Key-words : Water atomization, Silver, Powder, Sintering, Electrical property

[Received September 15, 2016; Accepted November 1, 2016]

\section{Introduction}

Silver powders are used in industrial applications as catalysts $^{1), 2)}$ and in electronic devices. ${ }^{3), 4)}$ They are particularly important for electrode preparation in low-temperature co-fired ceramics $^{5), 6)}$ and silicon solar cells. ${ }^{7,8)}$ Silver powders have been prepared for the above applications by chemical reduction, ${ }^{9), 10}$ atomization, ${ }^{11), 12)}$ or spray pyrolysis. ${ }^{13), 14)}$ In the case of chemical reduction, dispersants must be added to silver particles to prevent agglomeration after drying. Chemical reduction is also timeconsuming, as there are a number of processes involved, such as chemical reaction, separation, collection, and drying and it has a high environmental-load because a large amount of solvent is used. Atomization produces high purity silver particles in a short time without using a solvent and the starting powder can be used again by recycling. Gas atomization produces spherical particles with particle size larger than $10 \mu \mathrm{m}$. On the other hand, water atomization produces irregular particles with particle size smaller than $10 \mu \mathrm{m}$. In this method, high-pressure water breaks up a molten metal stream, which then solidifies into the metal powder. It is also possible to produce silver powder with spherical morphology and smaller sizes using spray pyrolysis. However, it is difficult to produce silver powder via spray pyrolysis on an industrial scale with high production efficiency, and it is necessary to treat exhaust gases such as $\mathrm{NO}_{\mathrm{X}}, \mathrm{Cl}_{\mathrm{X}}$, and $\mathrm{SO}_{\mathrm{X}}$. It has been reported ${ }^{15)-22)}$ that uniform and smaller metal powders were formed by controlling conditions such as nozzle type, pressure and water flow rate. So far, the metal powders described above have been produced by atomization under an air atmosphere. The air atmosphere leads to the oxidation of metal powder during the atomization. ${ }^{23)}$ We developed a water atomization apparatus in

\footnotetext{
Corresponding author: T. Ogihara; E-mail: ogihara@daiken-chem. co.jp
}

which the tundish and melting furnaces are shielded in a nitrogen atmosphere for the production of silver powder with low oxygen content. In this paper, the particle characterization and electrical properties of the silver powder produced through high pressure water atomization are described.

\section{Experimental procedure}

2.1 Preparation and characterization of silver powder by atomization

A schematic diagram of the high-pressure water atomization apparatus is shown in Fig. 1. This apparatus consisted of a fullcone type atomizer nozzle, tundish and melting furnaces, a water tank, and a filter press. The tundish and melting furnaces were shielded to maintain a nitrogen atmosphere. Silver products made using the Sasabuki silversmithing method were used as the starting materials. These silver products were placed into the tundish and melting furnaces and melted at higher than $1370^{\circ} \mathrm{C}$ by radiofrequency heating under a nitrogen atmosphere. $120 \mathrm{~kg}$ of silver products were melted at a time. Molten silver was flowed from the tundish nozzle and fractured by water at a pressure of $80 \mathrm{MPa}$ and a water flow rate of $220 \mathrm{~L} / \mathrm{min}$. The slurry of the silver powder was stocked in the water tank and introduced to the filter press by pump. The silver powder was then separated from the slurry by the filter press and dried at $60^{\circ} \mathrm{C}$ in the dry chamber. The as-prepared silver powder was classified to $2.5 \mu \mathrm{m}$ using a turbo classifier (Nisshin Engineering, TC-25). The particle morphology, microstructure, and agglomeration of the as-prepared silver powder were studied using a scanning electron microscope (SEM, JEOL, JSM-6510). The volume average particle size $\left(\mathrm{D}_{50}\right)$ was measured by a dynamic light scattering method (Nikkiso, MT3300EXII). The specific surface area (SSA) was measured using the BET method (Shimadzu, FlowSorb III 2305). The crystal phase of the as-prepared silver powder was identified using powder X-ray diffraction (XRD, Shimadzu, XRD-6100). 


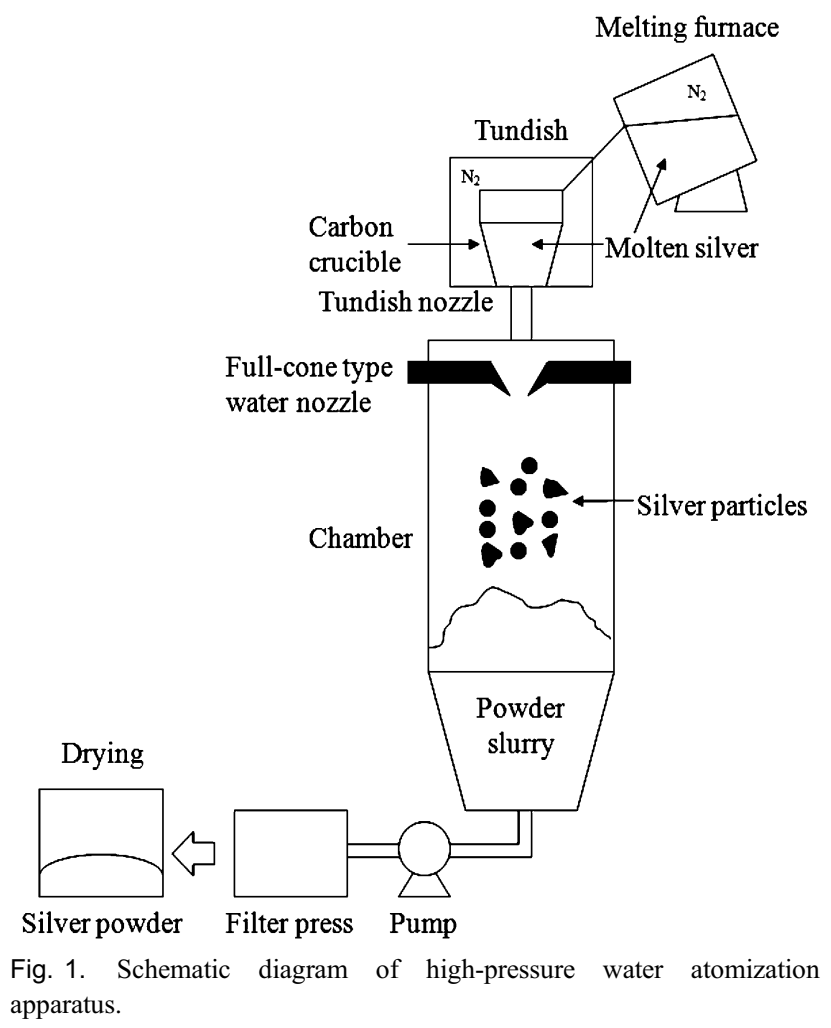

The oxygen concentration in silver particles was measured with an electron probe micro analyzer (EPMA, JEOL, JXA-8900RL).

\subsection{Preparation and characterization of silver paste}

After the silver powder was classified to the size of $\leq 2.5 \mu \mathrm{m}$, a silver paste was prepared with a three-roller mill. Ethyl cellulose resin was used as the vehicle and diethylene glycol monobutyl ether acetate was used as the solvent. The content ratio of silver powder, resin, and solvent was $85: 2: 13 \mathrm{wt} \%$. The viscosity of the silver paste was $200 \mathrm{~Pa} \cdot \mathrm{s}$. A $250-\mu \mathrm{m}$-thick film of the silver paste was coated on a PET film using a doctor blade. The silver paste was dried at $100^{\circ} \mathrm{C}$ for $2 \mathrm{~h}$ and then a $13 \mathrm{~mm}$ disk was cut from it. The disk was sintered at $500-900^{\circ} \mathrm{C}$ for $2 \mathrm{~h}$ under an air atmosphere. The microstructure of the disk was observed using SEM. The shrinkage of the disk was measured using thermomechanical analysis (TMA, Shimadzu, TMA8310). The resistivity $(R)$ of the disk was measured using a multi-meter (Mitsubishi, MCP-T360).

$$
\rho=\frac{R \times d}{l}(\Omega \mathrm{m})
$$

The thickness of the disk was measured using a surface roughness meter (Tokyo Seimitsu, Surfcom 130A) and then the specific resistivity $(\rho)$ was determined by Eq. (1), where $d$ is the cross-sectional area of the electrode and $l$ is the length of the electrode.

\section{Results and discussion}

\subsection{Powder characterization}

The particle morphology of the as-prepared silver powder is shown in Fig. 2. The SEM image shows spherical, elliptical, and irregular morphology and contains coarse particles, which were aggregated due to collisions after atomization. It is well known that metal particles often have an irregular morphology due to the rapid quench during water atomization. However, it is clear that

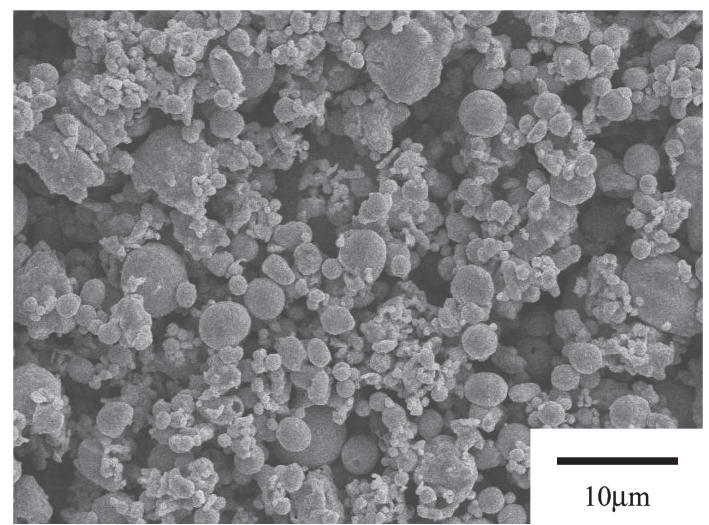

Fig. 2. SEM image of silver powder prepared by high-pressure water atomization.

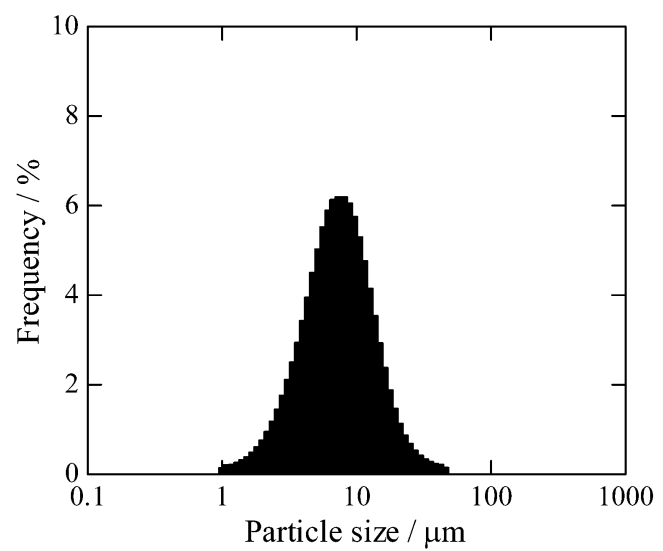

Fig. 3. Particle size distribution of silver powder prepared by highpressure water atomization.

many spherical particles were produced at high pressure and water flow rate. When water atomization was carried out at both high pressure and water flow rate, the molten silver was finely fractured and the particle size of the resulting silver powder was reduced. The particle size distribution of the as-prepared silver powder, shown in Fig. 3, followed a log-normal distribution. The volume average particle size $\left(\mathrm{D}_{50}\right)$ and its standard deviation were 8 and $4.1 \mu \mathrm{m}$, respectively. It was found that smaller particle sizes were produced at $80 \mathrm{MPa}$, as has been previously reported $^{24)}$ for metal powders produced with water atomization. Furthermore, this result suggested that high pressure and flow rate led to the formation of the silver powder with a relatively narrow particle size distribution. XRD patterns of (a) the asprepared silver powder and (b) the silver powder classified to the size of $\leq 2.5 \mu \mathrm{m}$ are shown in Fig. 4. The diffraction peaks seen correspond to silver (JCPDS Card No.04-0783) with a high crystallinity. There are no peaks associated with silver oxide present in the patterns. The crystallite size of the as-prepared silver powder was $39.8 \mathrm{~nm}$. This suggests that the silver powder consisted of smaller polycrystals. It is thought that the crystallization occurred slowly due to rapid quenching. The oxygen content of the silver particles determined by EPMA was $50 \mathrm{ppm}$. It is known ${ }^{14), 22), 23)}$ that metal powders derived from water atomization often exhibit high oxygen content, due to the powder taking in oxygen in the water during the fracture process. In this work, however, it was found that oxygen content in the silver powder was very low. The SSA of the silver powder was 


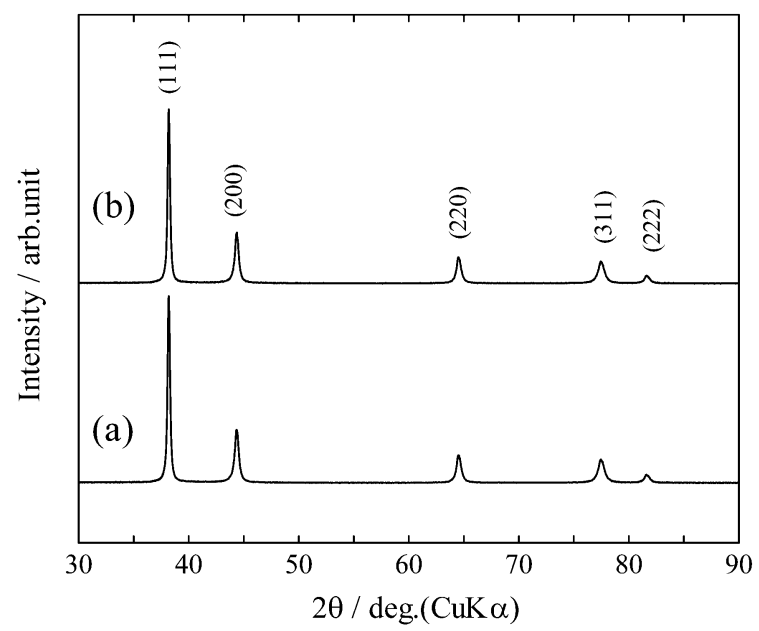

Fig. 4. XRD pattern of (a) as-prepared silver powder and (b) silver powder classified to $2.5 \mu \mathrm{m}$.

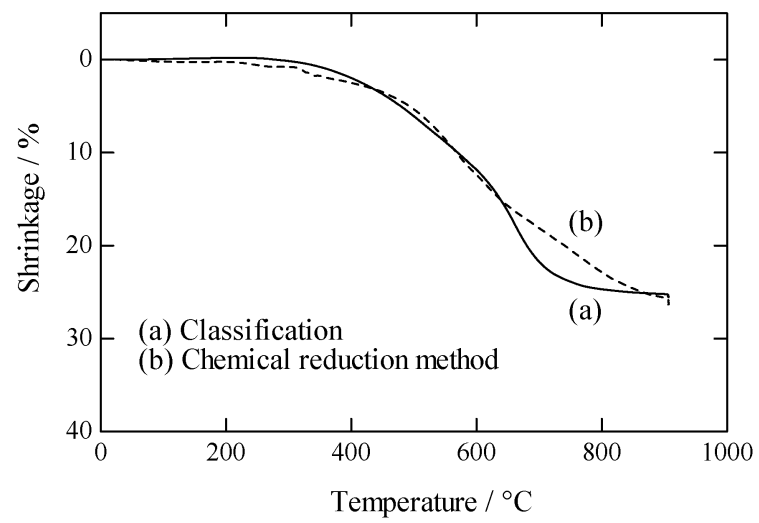

Fig. 5. TMA curves of silver powder obtained by classification (a) and reduction chemical method (b).

$0.23 \mathrm{~m}^{2} / \mathrm{g}$, which is smaller than that seen in previous studies. ${ }^{14)}$ Therefore, we consider that the oxygen adsorption ability of the powder was low because the SSA was small, and that the small SSA was a result of a significant increase in the primary particle content of the silver powder. As a result, we suggest that oxygen content taken in during the water atomization is significantly reduced since the SSA was small.

\subsection{Sintering and electrical properties}

Figure 5 shows shrinkage curves of silver pastes measured by TMA. The solid line in Fig. 5(a) is the shrinkage curve of the silver powder obtained by classification. The dashed line in Fig. 5(b) is the shrinkage curve of a silver powder derived from chemical reduction. The silver powders derived from both water atomization and chemical reduction began to shrink at $300^{\circ} \mathrm{C}$. The shrinkage of silver powder derived from atomization decreased sharply at $660^{\circ} \mathrm{C}$ and reached $25.5 \%$ at $900^{\circ} \mathrm{C}$. On the other hand, the shrinkage of the silver powder derived from chemical reduction decreased gradually and was $26.3 \%$ at $900^{\circ} \mathrm{C}$. After classifying the silver powders, the particle size and SSA of the silver powder derived from water atomization were $2.63 \mu \mathrm{m}$ and $0.43 \mathrm{~m}^{2} / \mathrm{g}$, respectively. The particle size and SSA of the silver powder derived from chemical reduction were $2.66 \mu \mathrm{m}$ and $0.38 \mathrm{~m}^{2} / \mathrm{g}$, respectively. The particle size and SSA of the silver powders were approximately equal, and consequently, the shrinkage of both was similar.
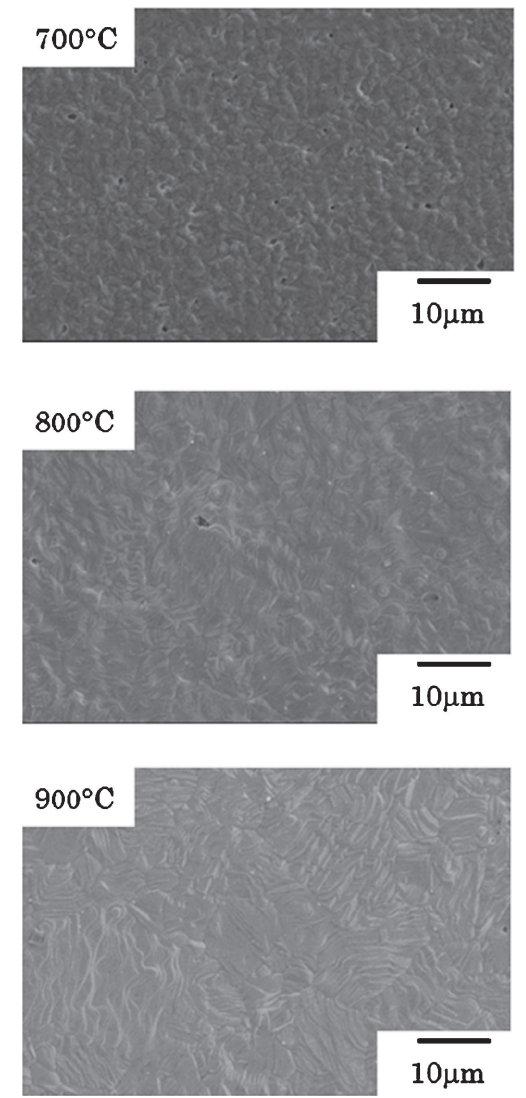

Fig. 6. SEM images of silver paste sintered for $10 \mathrm{~min}$ at 700,800 , and $900^{\circ} \mathrm{C}$.

The surface structure of the silver paste sintered at $700-900^{\circ} \mathrm{C}$ is shown in Fig. 6. The sintering time was $10 \mathrm{~min}$ at each sintering temperature. Pores can be observed in the silver paste sintered at $700^{\circ} \mathrm{C}$, with no apparent grain growth. Some grain growth is observed in the silver paste at $800^{\circ} \mathrm{C}$, while at $900^{\circ} \mathrm{C}$ the pores have disappeared and grains have grown even though the silver powder was classified. Metal powders with a broad particle size distribution generally lead to grain growth. In this work, we consider that grain growth occurred during the sintering because the silver powder still had a broad particle size distribution after classification.

The relationship between specific resistivity and sintering temperature was investigated to evaluate the electrical properties of the silver paste. Figure 7 shows the change in specific resistivity with the sintering temperature for different sintering durations. The specific resistivity of the silver paste sintered for $10 \mathrm{~min}$ decreased from $2.98 \times 10^{-8}$ to $2.15 \times 10^{-8} \Omega \mathrm{m}$ with increasing sintering temperature. It was found that the silver paste exhibited low resistivity of the order of $10^{-8} \Omega \mathrm{m}$, which is in agreement with that of the silver paste used for low-temperature co-fired ceramics. ${ }^{25)}$ The specific resistivity of the silver paste sintered for 60 min decreased from $2.33 \times 10^{-8}$ to $2.11 \times 10^{-8} \Omega \mathrm{m}$ with increasing sintering temperature. This resulted in the disappearance of pores in the silver paste due to grain growth. The silver paste exhibited low specific resistivity when the sintering temperature was high and sintering time was long. Silver powder derived from high-pressure water atomization is expected to become a standard electrode material for silicon solar cells, inductors, etc. in the future. 


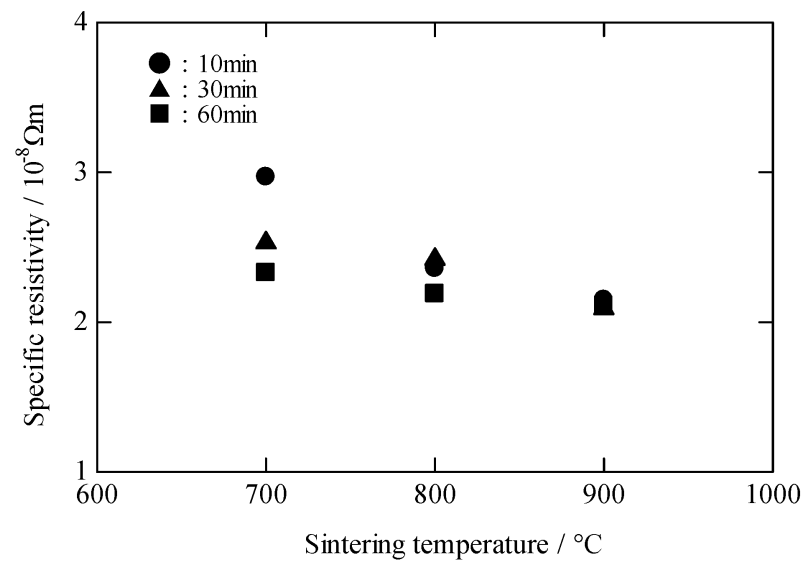

Fig. 7. Relationship between resistivity and sintering temperature for different sintering durations.

\section{Conclusion}

A silver powder was produced through water atomization with high water pressure and flow rate. As-prepared silver particles with volume average particle size of $8 \mu \mathrm{m}$ were aggregated and had various types of morphologies such as spherical, elliptical, and irregular. The as-prepared silver powder had a single phase with high crystallinity, and a very low oxygen content of $50 \mathrm{ppm}$. The TMA-measured shrinkage of the silver paste produced using water atomization was comparable to that of the paste produced using chemical reduction when the particle size and SSA of the silver powders were similar. The specific resistivity of the silver paste sintered at $900^{\circ} \mathrm{C}$ for $60 \mathrm{~min}$ was $2.11 \times 10^{-8} \Omega \mathrm{m}$.

\section{References}

1) T. Salmi, J. H. Carucci, M. Roche, K. Eranen, J. Wama and D. Murzin, Chem. Eng. Sci., 87, 306-314 (2013).

2) K. Yokozaki, H. Ono and A. Ayame, Appl. Catal., A, 335, 121-136 (2008).

3) P. M. H. Peter, H. M. Veit and A. M. Bemardes, Waste Manage., 34, 475-482 (2014).

4) K. S. Kim, K. H. Jung and S. B. Jung, Microelectron. Eng., 120, 216-220 (2014)

5) A. Bittner, H. Seidel and U. Schmid, Microelectron. Eng., 88,
127-130 (2011).

6) Y. Wang, G. Zhang and J. Ma, Mater. Sci. Eng., B, 94, 48-53 (2002).

7) P. Liu, S. E. Yang, Y. Ma, X. Lu, Y. Jia, D. Ding and Y. Chen, Mater. Sci. Semicond. Process., 39, 760-763 (2015).

8) J. T. Tsai and S. T. Lin, J. Alloys Compd., 548, 105-109 (2013).

9) K. S. Chou and C. Y. Ren, Mater. Chem. Phys., 64, 241-246 (2000).

10) B. An, X. H. Cai, F. S. Wu and Y. P. Wu, Trans. Nonferrous Met. Soc. China, 20, 1550-1554 (2010).

11) A. T. Ankus and R. D. Venter, Powder Technol., 73, 169-179 (1992).

12) Y. Kato, J. Jpn. Soc. Powder Powder Metallurgy, 61, 465-472 (2014).

13) T. C. Pluym, Q. H. Powell, A. S. Gurav, T. L. Ward, T. T. Kodas, L. M. Wang and H. D. Glicksman, J. Aerosol Sci., 24, 383-392 (1993).

14) A. Kato, A. Takayama and Y. Morimitsu, Nippon Kagaku Kaishi, 12, 2342-2344 (1985).

15) M. Nitta, K. Ogura, S. Saito and H. Sugihara, KAWASAKI STEEL GIHO, 24, 290-295 (1992).

16) B. Bergquist and T. Ericsson, Powder Metall., 43, 37-42 (2000).

17) M. Mitsutsuka and K. Fukuda, Transactions ISIJ, 21, 596-602 (1981).

18) S. Sekino, M. Yamamiya and T. Nishida, Tetsu To Hagane, 67 , 541-546 (1981).

19) T. Takeda and K. Minagawa, J. Jpn. Soc. Powder and Powder Metallurgy, 38, 796-799 (1991).

20) K. Suzuki, T. Kondoh and T. Shimizu, Denkiseiko, 69, 137140 (1998).

21) M. Kikukawa, S. Matsunaga, T. Inaba, O. Iwatsu and $T$. Takeda, J. Jpn. Soc. Powder and Powder Metallurgy, 47, 453457 (2000).

22) I. Endo, R. Okuno, H. Satake, I. Otsuka, H. Yamamoto, A. Shintani, M. Yoshino and M. Yagi, J. Jpn. Soc. Powder and Powder Metallurgy, 48, 697-702 (2001).

23) H. Toyoshima, T. Shimura, A. Watanabe and H. Otsu, J. Jpn. Soc. Powder and Powder Metallurgy, 52, 437-441 (2005).

24) M. Kikukawa, S. Matsunaga, T. Inaba, O. Iwatsu and $T$. Takeda, J. Jpn. Soc. Powder and Powder Metallurgy, 47, 453457 (2000)

25) A. Okada and T. Ogihara, Key Eng. Mater., 421, 289-292 (2010). 